\title{
The Morphosyntactic Structure of the Noun and Verb Phrases in Dholuo/Kiswahili Code Switching
}

\author{
Jael Anyango Ojanga (Corresponding author) \\ Department of Languages: Sugar Research School, Kisumu, Kenya \\ E-mail: Jaelanyangoojango@yahoo.com \\ Furaha Chai \\ Department of Literature, Language and Linguistics, Faculty of Arts and Social Science: Egerton University, Kenya \\ E-mail: optiondz@yahoo.co.uk \\ James Mutiti \\ Department of Literature, Language and Linguistics, Faculty of Arts and Social Sciences: Egerton University, Kenya \\ E-mail: Yakuti56@yahoo.com
}

Doi:10.7575/aiac.alls.v.6n.2p.30

URL: http://dx.doi.org/10.7575/aiac.alls.v.6n.2p.30
Received: 08/11/2014

Accepted: 14/01/2015

\begin{abstract}
Code switching, the use of any two or more languages or dialects interchangeably in a single communication context, is a common linguistic practice owing to the trend of multilingualism in the world today. In many situations of language in contact, constituents of one language can be found within the constituents of another language in a number of linguistic phenomenon namely lexical borrowing, transferring, interference, code switching and diffusion (Annamalai, 1989). Codeswitching is one of the linguistic phenomenon claimed to be the most prevalent and common mode of interaction among multilingual speakers. Brock and Eastman (1971) suggest that topic discussed influences the choice of the language. Nouns and verbs have been found to be the most code switched elements in bilingual exchange. The study took a qualitative approach with the descriptive research design. It was guided by the Matrix Language Frame Model which was formulated by Myers-Scotton in1993. This model expounds on the realization and structure of the major word classes as used in code switching. Data was collected in Nyangeta Zone, Winam Division of Kisumu East District. Winam Division is mostly inhabited by elite Dholuo L1 speakers. A sample of twenty four teachers was purposively selected to provide data needed for the study. Focus group discussion was used to collect a corpus of Dholuo/Kiswahili data which was recorded through audio taping. The recorded data was then analyzed morphosyntactaically using the Matrix Language Frame Model. The data revealed that the noun and verb phrases were realized under three categories: Matrix Language Island constituent (ML Island) ML+EL and Embedded Language Island (EL Island.
\end{abstract}

Keywords: Code switching, multilingualism, morphosyntactic

\section{Introduction}

An intriguing aspect of language contact is to consider what happens to the structure of the word classes of language when their speakers are bilingual and their speech brings two or more languages into contact. The goal of this article is to analyse the grammatical structure of utterances in code switching that are inherent in the Matrix Language Frame model of Myers-Scotton (1993a, 1997 and 2002). Code switching as used in this document refers to the mixing, by bilinguals (or multinguals), of two or more languages in a discourse. The data to be used here comes from urbanized elite Luo Dholuo L1 speakers, who have attained a minimum of secondary education and have also trained as teachers who are bilingual in Kiswahili.

Dholuo, a language spoken by the Luo (also spelled as Lwo) is a Nilotic language spoken by the fourth largest linguistic group in Kenya (Ogot 1967). The Luo are several ethnolinguistically related ethnic groups in Africa who inhabit an area ranging from South Sudan and Ethiopia, through northern Uganda and Eastern Sudanic (Nilotic language, a branch of the Nilo-Saharan language family.

The people who speak Luo language include the Shilluk, Anuak, Acholi, Jurluo, Lango, Palwo, Alur, Padhola, Joluo (Kenyan and Tanzanian Luo), Bor and Kuman. According to ethnologists, linguists, Luo oral history, the Luo are part of the Nilotic group of tribes who separated from the other members of the East Sudanic family by the $3^{\text {rd }}$ millennium B.C. (Bethwel Ogot places the area of origin of the Luo in South Sudan). More than eight centuries ago, the Luo people occupied the area that now lies in present day eastern Bar-el-Ghazal, South Sudan.

The Luo moved to nearly all the countries neighbouring Sudan, resulting in many separate groups with same language and traditions. Between 1500 and 1800, other Luo groups crossed into present day Kenya and eventually into present 
day Tanzania. They inhabited the area around Lake Victoria. According to Joluo, a warrior chief named Ramogi Ajwang led them into present day Kenya about 500 years ago. As in Uganda, some non-Luo people in Kenya have adopted Luo language. The Luo in Kenya, who call themselves Joluo (aka "Jaluo- people of Luo") are the $4^{\text {th }}$ largest community (with a population of about 4,440,044) after Kikuyu, Kalenjin and Luhyia. (Government of Kenyan Census Report 2010). The Luo in Kenya settled on the shores of Lake Victoria, in Nyanza province which is located on the Western part of Kenya. The Luo are a River- Lake Nilotic speaking community who had moved from Southern Sudan through Uganda to their present territory on the Eastern shores of Lake Victoria (Ochieng'1979).

According to Ogot (1967), the Luo travelled one thousand miles for nearly one thousand years through seven cradles of evolution, three in the Sudan and four in Uganda. Finally the composite society went through an intense societal revolution between 1750-1900 before colonialism set in, emerging as a cohesive Luo community. The Luos are neighbours to the Bantu language speakers, the Luhyas (Samia, Banyala, Marachi, Banyore, and Maragoli) and the Nandi to the North, the Kipsigis to the East, the Gusii and Kuria (both Bantu) to the South East of Kenya and the Shirati and Waswa (Bantus) people to the Northern Tanzania.

According to Stafford (1967), Dholuo has two major regional varieties:

a) The Trans-Yala dialect-spoken in Ugenya, Alego, Yimbo and parts of Gem.

b) The Trans-Kuja dialect, spoken in the various locations of Southern-Nyanza area plus those parts of Siaya and Kisumu not included in the Trans-Yala group.

Although these dialects of Dholuo have a high degree of mutual intelligibility, they are distinct enough in their lexical and phonological features to enable one identify a dialectal zone a speaker comes from merely by the way he speaks (Ochieng 1979). The South Nyanza variety is the one that has been used in the bulk of the literature, including the Bible and readers for schools. Today the Luo people practice a mixed economy, involving agriculture, fishing, livestock rearing etc. Many of them are also to be found in diverse professions and vocations.

Swahili on other hand belongs to the North-East Coastal Bantu group of the Benue-Congo family, which is a member of the Niger-Congo group of languages, one of the largest families of languages in Africa (Campbell 1991). The name 'Swahili' is derived from the Arabic word 'Sawahil' which means Coast. There seems to be evidence of Swahili being spoken in the East Coast of Africa centuries before the arrival of Europeans.

Miehe (1995) also suggests that Swahili had its origin at the East Coast of Africa in the period before the $10^{\text {th }} \mathrm{c}$. Four separate but hardly exclusive groups were found in this area: the "pure-blooded Arabs or Persians", The Afro- Arabs, of mixed blood, the Islamized Africans and non- Islamized Africans from outside the Coastal area. As a result of intermarriage and closer interaction, it became difficult over the years to differentiate between those groups, and so the term "Waswahili" was used to refer to them (Miehe 1995).

The Arab traders later on set up interior trading centres which served as stopping depot for slaves in transit and for purchase of locally available ivory. They also founded dynasties to help facilitate their trade. Whitely (1969) records that Swahili, the language of the coastal traders eventually spread inland along the trade routes and inland centres they founded.

During the colonial period, the use of Swahili improved. It was widely used by the colonial administration for administrative purposes. In education, it is used both as a medium of instruction and also taught as a subject. Recent estimates put the speakers of Swahili to be between 50 and 70 million people, the great majority of whom are bilinguals, using Swahili as a second language alongside other African languages (Campbell 1991).

\section{Morphosyntactic structures of code switched elements}

The word morphosyntactic is an adjective of morphosyntax. Morphosyntax is derived from morphology which is the study of word formation and syntax which is the study of how words are combined into larger units such as phrase and sentences. According to Crystal (1980) Morphosyntax is a term used in linguistics to refer to grammatical categories/ properties for whose definition criteria of morphology and syntax both apply as in describing the characteristics of words. Morphosyntactic structures of utterances in Dholuo/ Kiswahili code switching were realized under three categories: ML+EL Constituents, ML Constituents and EL Constituents. These three types of constituents are different though they are interrelated through the constituents governing them.

\section{ML+ EL Constituents}

ML+EL Constituents consists of morphemes from both the matrix language (ML) and the Embedded language (EL). The prototypical ML+EL constituents contain a singly occurring EL lexeme in a frame of any number of ML morphemes.

E.g in sentence

\section{An ok ahero porojo mang'eny.}

(I don't like too much disturbance)

The sentence has four morphemes from the matrix language Dholuo-(an, ok, ahero, mang'eny) against only one morpheme from the embedded language, Kiswahili (porojo). The singly occurying EL morpheme is the NP porojo embedded in the structure of the matrix language. 


\section{ML Island Constituents}

The ML Islands are constituents consisting entirely of Matrix Language Morphemes. They must be well formed constituents according to the Matrix Language grammar and must show internal structural dependency. In this research the matrix language is Dholuo Language and so the ML Islands must be well formed according to the internal structure of Dholuo language. E.g in sentence

29 Thoth nyithindo matiyo matek e klas.

(Most of the children who work hard in class).

This sentence has been realized as a nounphrase in ML. The determiner thoth (many), the noun nyithindo (children) and the verb tiyo (working) have all been realized in the ML and even the surface word structure is that of the matrix language.

\section{EL Island Constituents}

The EL Island may supply what is called EL Island. These EL Island are monolingual EL phrases that are grammatically well formed in the EL (they include inflections). In this study the embedded language is Kiswahili. E.g in sentense 39

$$
\text { Kwa nini unamringia hivyo? }
$$

(Why are you so boastful to him?)

\section{ML+EL, ML and EL Structure of the Noun Phrase}

Evidence attested in our corpus of Dhuluo/Kiswahili code switching shows that noun phrases are realized at virtually all the three constituents (ML Islands, EL Islands and ML+EL Constituents) though with varying constraints. However, they are more likely to occur as single morphemes in the EL. For descriptive purposes, we will consider sentences that exemplify the occurrence of the nouns as Islands as we discuss the nouns in the ML+EL constituents. The following examples of sentences numbered 1, 15, 21 and 49 are used to highlight the occurrences of nouns as ML+EL, ML Islands and EL Islands.

\section{1) To ajali marach notimore e barabara kubwa madhi Kakamega.}

(But accident that other happened on the road big which goes to Kakamega) for

(That bad accident happened on the main road to Kakamega.

\section{To ajali marach notimore e barabara kubwa madhi Kakamega has two}

Phrases:

Ajali marach (a bad accident) is an ML+EL constituent as it comprises a morpheme each from the two participating languages involved in the code switching. Ajali is Swahili word for accident while marach is Dholuo word for (very bad). As stated in the MLF Frame model, the constituent has adopted the Matrix Language Frame Model's proposition that the ML+EL Constituents must adopt the Matrix Language Structure. This sentence has adopted Dholuo language structure where a noun is post modified by the adjective it has occurred with. The noun ajali has been postmodified by the adjective marach.

Barabara kubwa (main road) is the other noun phrase realized as an EL Island comprising two Kiswahili words barabara and kubwa for (the main road and big). It is important to note that the NP in the EL constituent takes the morpheme order of the embedded language, Kiswahili which like Dholuo has the main noun barabara being post modified by the adjective kubwa it has occurred with.

The above sentence has Dholuo as the matrix language since it has produced the highest number of morpheme in the structure - 4 morphemes (morono, notimore, e, madhi) while Kiswahili, the embedded language has produced only three morphemes (-ajali, kubwa and barabara)

15) Katiba manyienni to ber nikech omiyo ng'ato ka ng'ato hakine.

(Constitution new this one is good because it gives each person his right) for (This new constitution is good as it grants each individual his/her rights).

This sentence has three main noun phrases: Katiba manyienni, ng'ato ka ng'ato, hakine.

Katiba manyienni (constitution new this) for (this new constitution) has been realized as an ML+EL Constituent. The main noun katiba has been postmodified by a Dholuo adjective manyienni (this new one)

The second nounphrase ng'ato ka ng'ato (every person) is a Dholuo morpheme realized as an ML island and it has taken Dholuo structure where a morpheme may be doubled for emphasis. 
The third noun phrase has been realized as an ML+EL morpheme where the main noun hakine (right) has a prefix $n e$ (his/hers) which refers back to the noun haki. As stipulated in the MLF model when a morpheme is realized as an ML+EL it must take the morpheme order of the matrix language. The suffix ne has been attached to the main noun haki because of the agglutinative nature of the Dholuo language.

The above sentence has Dholuo as the matrix language since it has contributed the highest number of morphemes- 8 (manyienni, to ber, nikech, omiyo, ng'ato, $k a$, ng'ato) while the embedded language Kiswahili has contributed only two morphemes-(katiba and haki)

\section{1) Ndik andika maneno mawili matatu hivi e baruwano, jonyuol go bende onge gi} wakati mar somo gigo te.

(write words two three like this inside that letter those parents also do not have with time for reading those things all) for ( just write two or three words in that letter as those parents do not have time to read all those things.)

The sentence Ndik andika maneno mawili matatu hivi e baruwano, jonyuolgo bende onge gi wakati mar somo gigote has three main noun phrases:

Maneno mawili matatu hivi is an EL Island NP Constituent comprising four morphemes-maneno, mawili, matatu, hivi for (two or three words like these) and it has taken the word order of Kiswahili language where a noun is post modified by the demonstrative it has occurred with. In this sentence the demonstrative hivi (these) has post modified the noun phrase maneno mawili matatu.

The second noun phrase baruwano (letter that) for (that letter) has been realised as an ML+EL constituent because it has one Kiswahili morpheme which has been agglutinated with a demonstrative (no) for (that) from the Dholuo Language. Barua refers to a letter in Kiswahili while no refers to the demonstrative that in Dholuo. As stipulated in the MLF model, all nouns captured as ML constituents must take the morpheme order of the matrix language which in this case is Dholuo language and all the system morphemes always come from the matrix languange.

In the above sentence, system morpheme like the demonstrative (that) in that letter (baruwano) has been realized as an ML constituent. Baruwano (letter that) for (that letter) has taken the word order of Dholuo where a noun is postmodified by the demostrative it co-occurs with.

The third nounphrase gigote (those things all) for (all those things) has been realized as an ML Island and it has followed the word order of the Dholuo .langauge.

The above sentence has Dholuo as the matrix language since it has contributed the highest number of morphemes: tweve morphemes (ndik, andika, jonyuol, go, bende, onge,gi, mar, somo, gigo,te.) while Kiswahili, the embedded language has contributed five morphemes ( maneno, mawili,matatu,wakati, hivi.). It should be noted that the word barua (letter) is a Kiswahili word for a letter and it has been incorporated into Dholuo language where it has acquired Dholuo system of pronunciation where the last letter $\mathbf{a}$ in a morpheme is pronounced as wa.

\section{9) Wananchigi bende changia ufisadi matimore e Kenya kae.}

(Citizens these also contribute corruption those happening Kenya here) for

(These citizens also contribute to the corruption cases which happen here in Kenya.

This sentence has three main noun phrases:

Wananchigi (citizens these) for (these citizens) is an ML+EL noun phrase because it has two morphemes from the two languages used in code switching i.e wananchi is a Kiswahili word for citizens and gi is a Dholuo word meaning these. As posited in the MLF model, the noun phrase has taken the morpheme order of the matrix language, Dholuo where the noun and the determiner have been agglutinated to form one word, wananchigi. The Dholuo morpheme $\boldsymbol{g} \boldsymbol{i}$ for (these) has also postmodified the noun it has occurred with.

The second noun phrase which has been captured in this sentence is ufisadi matimore (corruption happening) for (corruption which is taking place) is also an ML+EL because it also has two words from the two languages which have been used in the codeswitching i.e ufisadi is a Swahili word for corruption and matimore is a Dholuo word for which is happening.

The last noun phrase which has been realised in the sentence is Kenya kae (Kenya here) for (here in Kenya). The noun phrase has taken the word order of the matrix language, Dholuo where the adverb of place kae (here) has post modified the noun Kenya, which it has occurred with.

Considering the above examples, it is evident that whenever the nouns occur in the ML+EL constituent, the noun is in EL and the word order which is adopted is that of the matrix language while in an island constituent, it occurs in EL or ML for EL and ML island constituents respectively. This is in accordance with MLF model, which consider nouns as content morphemes and posits that most of the times the EL may occur as single lexeme in any frame of the ML morphemes. 


\section{ML+EL, ML and EL Structure of the verb phrase}

According to our corpus, the occurrence of the verb in either ML+EL, ML or EL in Dholuo/Kiswahili code switching is dependent on the constituent area in which it is realized. Where the main verb is in an Island constituent occurring either as ML or EL constituent, it occurs in the respective language of the Island constituent that is the main verb will be in EL or ML if it occurs in EL Island and ML Islands respectively. The following sentences numbered 6, 20, 23, 26 and 27 are given as illustrations to exemplify the realizations of the verb Phrase.

\section{Sentence 6) Otieno to pok otembeleaga koro kik obabaika}

(Otieno but not visited me so he not need not worry) for

(Otieno has not visited me so he need not worry)

In the sentence, there are two main verb phrases: Pok-o- tembelea-ga and kik obabaika which have both been realized as ML+EL constituents.

The sentence has pok-o-tembelea-aga (has never visited me) as an ML+EL constituent with the main verb tembelea premodified by $o$ (him) in (otembelea) to mark number (third person singular) and post modified by $\boldsymbol{a}$ (me) in pok-otembelea- $a$ and $g a$ ( always) to mark the progressive aspect. As proposed in the MLF model, when a verb occurs as an ML+EL constituent it takes the word order of the matrix language which in this case is Dholuo.

The other main verb babaika has also been realized as an ML+EL constituent, i.e the main verb babaika has been premodified by $\mathbf{o}$ in obabaika to mark person ( $3^{\text {rd }}$ person singular). The verb has also taken the word order of the Dholuo language where person premodifies the verb attached to it because of the agglutinative nature of Dholuo language.

In the sentence, Otieno to pok otembeleaga koro kik obabaika also confirms to the matrix language model's proposition in the Matrix Language Frame Model that the matrix language must produce the highest number of morphemes. Dholuo which is the matrix language in this sentence has produced seven morphemes (bende, pok, o, $a$, koro, kik $o$,) and the embedded language, Kiswahili has produced two morphemes (tembelea and babaika).

\section{Sentence 23 Kata Muma bende wachoni wakumbushwe tu kata gingeyo kamano}

(Even the Bible also says remind them just even if they know like that) for

(Even the Bible says just remind them even if they know)

In the above sentence, there are two verbs phrases i.e wacho $n i$, (says that) and wakumbushwe tu (just be reminded). Wachoni (says that) has been realized as an ML Island in the sentence kata muma bende wacho (even the Bible says).

There other verb phrase wakumbushwe tu has been realized as an EL Island and as proposed in the MLF mode, when a verb occurs as an ML or EL Island it takes the word order of the language in which it has been realized.

In the above sentence, Dholuo, which is the matrix language has contributed eight morphemes-(kata, Muma bende, wacho, ni, kata, gingeyo and kamano) compared to Kiswahili that has only contributed only two morphemes(wakumbushwe, tu).

The EL Island wakumbushwe tu has the main verb wakumbushwe in the EL language. The same thing has happened in Dholuo verbs, bende wacho (also says), both in Dholuo, ML Island constituent.

\section{Sentence 26 Asewinjo watangazaji wengi kaketho Kiswahili marach}

(I have heard announcers many when spoiling Kiswahili badly) for

(I have heard many news presenters speak ungrammatical Kiswahili).

There are two verb phrases captured in the above sentence asewinjo (I have heard) and kaketho (when spoiling). These verb phrases have been realized as Matrix Language constituents.

Kiswahili, the embedded language has contributed only two morphemes- watangazaji (newsmen) and wengi (many). As proposed in the MLF model the system morpheme has been realized in the matrix language.

\section{Sentence 27 (Jopuonjgo to be ozidi gi kwayo pesa penj ma kila mara}

(Teachers those ones are too much with asking for exams money all the time) for

(Those teachers are now too much with their demand for exam money all the times)

In the sentence there is only one verb which has been realized as an ML+EL constituent. The sentence has jopuonjgo go to be ozidi (Those teachers are now too much). Ozidi is realized as an ML+EL constituent with the main verb zidi in Kiswahili, the embedded language and $\boldsymbol{o}$ (they) to mark number - plural for those teachers. As proposed in the MLF 
Model, when a verb occurs as an ML+EL constituent, the main verb must take the word order of the matrix language. This is why the main verb zidi has been premodified by $\mathbf{o}$ to mark third person plural in reference to the teachers.

The sentence has Dholuo as the matrix language since it has produced the highest number of morphemes- 8 morphemes (jopuonj, go, to, be, o, gi, penj, ma) against the embedded language Kiswahili which has only produced only 3 morphemes (zidi, kila, mara).

Sentence 38 (Ok a amini ni ng'ato nyalo paro gima kamano wacha kuthubutu

\section{kutenda.}

(I dont believe that someone can actually think of such a thing let a lone doing

it.)

The main verb phrases in this sentence are $o k a$ amini (I don't believe), nyalo paro (can imagine) kutenda (doing).

$O k a$ amini has been realized as an ML+EL constituent with $a$ (i)-pronoun for first person singular premodifying the main verb it has occurred with thus following the Dholuo word order where a pronoun always premodifies the verb.

The other two verbs nyalo paro (can imagine) and wacha kuthubutu kuitenda (Let a lone doing it) are ML and EL morphemes that have been fitted into the the ML structure where they don't go against the word order of the matrix language.

It is important to note that in the data above, whenever a main verb occurred in the ML+EL constituent it took the morphological structure of the host language thus the agglutinative nature of Dholuo is exemplified in the sentence 6 and sentence 26 above. The verbs in these sentences pok otembelea $a g a$ (he has never visited me), obabaika (he need not worry), and ozidi (they are too much) have inflectional typology of the host language, Dholuo which agglutinates the subject and the object on the main verb. All the inflectional morphemes are ML+EL constituents since they all have morphemes from the two participating languages i.e. Dholuo and Kiswahili. These ML+EL constituents however pick the morpheme order of the host language which supports the morpheme order principle which states that in ML+EL constituent, the morpheme order will be that of the matrix language.

\section{Conclusion}

This study set to out to analyse the morphosyntactic structures of noun and verb phrases in Dholuo/Kiswahili code switching and to determine the extent to which the MLF model is adequate in the analysis of such data. The study used the MLF model to analyse intrasentential code switching data from Dholuo/Kiswahili code switching data. The study hypothesized that the principle and the tenets of the model would be applicable to Dholuo/Kiswahili code switching data and that Dholuo would be the matrix language in Dholuo/Kiswahili code switching.

Evidence attested in our corpus of structure of utterances in Dholuo/Kiswahili code switching shows that noun phrases are realized virtually at all the three constituents (i.e. the ML Islands, EL Islands and ML+EL constituents) though with varying constraints. However, they are more likely to occur as single morphemes in the EL.

With verbs, the realization is either as ML or EL in Dholuo/Kiswahili code switching is dependent on the constituent area in which it is realized. Where the verb is in an Island constituent, ML or EL it occurs in the respective language of the Island constituent that is the main verb will be in EL or ML if it occurs in EL Island and ML Island respectively. On the other hand, whenever the verb phrase was part of the ML+EL constituent the verb occurred in the EL although it was inflected to agree with tense and aspect of the constituent in our corpus. It was realized in some ML+EL constituents as an EL while in others as an ML.

\section{References}

Annamalai. E. (1989) The Language Factor in Code mixing. International Journal of Sociology of Language.

Brock, B.R. \& Eastman, C.H .(1971) Markers, Pauses and code switching in bilingual Tanzanian Speech. General Linguistics.

Campbell, G.L. (1991) Compendium of Worid's Language, Vol 2. London: Routledge

Chimerah, R. (1998) Kiswahili: Past, Present and Future Horizons. Nairobi: NairobiUniversity Press.

Crystal, D. (1980) A first Dictionary of Linguistics and Phonetics: Colorado: West view Press, Boulder.

Census Report (2010) Government of Kenya Census Report

Myers-Scotton, C. (1993a) Social Motivation for Code switching; Evidence from Africa, New York: Oxford University Press.

Myers- Scotton, C. (1993) Duelling Languages: Grammatical Structures in Code Switching. Oxford: Oxford University Press.

Myers- Scotton, C. (1993b) Duelling Languages: Grammatical Structures in Code Switching. Oxford: Oxford University Press

Myers-Scotton, C. (2002) Contact Linguistics: Bilingual encounters and grammatical outcomes. Oxford: Oxford University Press. 
Ochien'g, W. (1979) People around The Lake. Nairobi. Evans

Ogot, B.A. (1967) History of the Southern Luo: vol 1, Migration and Settlement 1500-1900, (Series: People of East Africa), East African Publishing House, Nairobi, Kenya

Stafford, R.L. (1967) An Elementary Dholuo Grammar with Vocabularies. Nairobi. OUP.

Whiteley, W.H. (1969) Swahili: The Rise of a National Language. London; Methuen \&Co. 